\title{
Symbolism and Magical Acts
}

\author{
By SVEIN BJERKE
}

1. However the field of magic in non-literate cultures is delimited and defined, probably most students of comparative religion and anthropology today conceive magic as falling either wholly or partly within the broad field of religion. While many writers on the subject endorse the Frazerian two principles of magic - the imitative and the contagious-few agree with his conception of magic as the primitive equivalent of our science. Now if people do not look upon their magic as technology pure and simple and consequently do not view the relationship between the rite and its effect in a mechanistic-causal manner, how in fact is the relationship thought of? Why do people believe in the efficacy of magical acts? And how can we explain this belief? Various answers have been given to these questions, but in this brief paper I have chosen to concentrate on the presentation and criticism of one particular analytic framework closely associated with the discipline of social anthropology. The British philosopher Skorupski has given the name "symbolist" to this approach because its adherents consider magical and religious actions and beliefs to be systems of messages cast in symbolic codes, about the social (and in some cases also the natural) order $^{1}$. This approach has also been called neo-Durkheimian ${ }^{2}$. The study of magic does not occupy any privileged position in this analytical framework, but I have focused on it here because I am of the opinion that precisely the study of magical acts and ideas provides us with a touchstone for probing the validity of the symbolist approach in general. There exists several varieties of the symbolist approach but in this paper I have chosen to concentrate on Beattie's theory. This because his anthropology can be characterized as "orthodox", and because in several publications he has succeeded in formulating his variety most forcefully and explicitlyalso with reference to magic ${ }^{4}$. But before I give a brief account of his theory I shall try to outline a few features which I think are central to symbolist theories of magic and religion.

a. In the old debate concerning differences and similarities between the modes of thought of traditional and modern societies-a debate that is still going on $^{5}$ - the symbolists, like Durkheim, maintain that there is no fundamental difference in this respect between traditional and modern societies. The symbolist approach tends to understand traditional religions on the

1 Cf. Skorupski $18 \mathrm{ff}$.

2 Cf. Runciman 153.

3 Cf. Peel 73.

${ }^{4}$ Cf. Beattie 1964, 65 ff., $202 \mathrm{ff}$; 1966, $60 \mathrm{ff}$; $1970,240 \mathrm{ff}$.

${ }^{5}$ Cf. Modes $1 \mathrm{ff}$, 
model of 20th century western Christianity for which science, not God, serves to explain events in this world of space and time. Religious convictions and dogmas are not really concerned with the empirical world but with metaphysics, and are thus not subjected to any criteria of verification or falsification ${ }^{6}$. A sharp contrast is seen between magic and religion on the one hand, and science on the other, a contrast that is neo-Durkheimian rather than Durkheimian ${ }^{7}$. The intellectualist, neo-Tylorian thesis that religion in traditional societies has an essentially explanatory function is most emphatically denied.

b. Emphasis is placed on magic and religion as forms of action. The term "ritual" is basic, denoting magico-religious actions as well as beliefs, values and attitudes. Action is prior to belief and myth which are often conceived as rationalizations of ritual activities. Belief, therefore, cannot explain ritual activity, on the contrary it is part of forms of activity. It is this totality that should be explained.

c. Ritual is symbolic. In so far as beliefs are not mere rationalizations, these are symbolic as well. This means that in general a distinction must be drawn between the conscious and explicit level of the actor, the literal meaning, and the level on which such acts and beliefs must really be understood. Magical and religious acts cannot be understood adequately in the actor's frame of reference-that is, on the literal level-the real meaning must be sought on a symbolic level which is most often hidden from the consciousness of the actor. Thus when an African villager kills a goat, the meaning on the literal level may be that he is making a sacrifice to his ancestors. But the symbolists maintain that what the man is really doing is to make a statement on lineage structure and values. "Ritual" in any given society constitutes a symbolic system which describes, demonstrates, or expresses social relations, groups, categories and values. Or, to quote Leach's well known dictum to the effect that "ritual action and belief are alike to be understood as forms of symbolic statement about the social order"s.

Ritual acts are thus not primarily ways of "doing" something, they are ways of "saying" something. This also applies to magical acts. On the literal level they are admittedly ways of doing something, often something very definite and practical, but symbolist theory demands that they are basically ways of saying something. The contrast between Frazer's conception of magic as the primitive equivalent of our science, and that of the symbolists as a kind of language, could hardly be greater.

2. When we now turn to Beattie and his theory of magic, it is first of all necessary to point out the distinction he makes between two kinds of human

${ }^{6}$ Cf. Leach $1969,107 \mathrm{f}$.

${ }^{7}$ Cf. Horton $258 \mathrm{ff}$.

${ }^{8}$ Cf. Leach 1954, 14. 
behaviour which he calls expressive and instrumental. This distinction is crucial to his theory of ritual-it is the foundation on which it is built. "Instrumental behaviour must be understood in terms of the consequences it aims at and achieves; expressive behaviour in terms of the meanings, the ideas, it expresses." "9 As examples of instrumental behaviour he mentions various agricultural techniques with associated empirical knowledge $^{10}$, the wearing of clothes and wielding authority ${ }^{11}$. Religious and magical behaviour belongs to the expressive category. Although it is analytically of the utmost importance to distinguish between these two kinds of behaviour, in real life instrumental activities often have expressive aspects, and expressive activities instrumental aspects.

At this point it should be emphasized that Beattie considers the category expressive behaviour to include also kinds of activities other than magic and religion. His category "ritual" is delimited by being related to beliefs in non-empirical powers, whether personalized or not ${ }^{12}$, a definition agreed upon by most anthropologists. He thus does not share the position of Leach whose category "ritual" comprises all expressive acts (and expressive aspects of "technical" acts), such as custom, etiquette, and ceremonial. According to Leach, the difference between social communicative behaviour in general and magical and religious behaviour, is either illusory or trivia ${ }^{13}$. Beattie emphasizes that ritual is more than expressive, it is also symbolic. Ritual is consequently characterized by a symbolism that is not necessarily characteristic of non-ritual expressive or communicative behaviour. A decisive importance is thus given to the concept of symbol which is a particular type of signs, that is "things that have meanings and which stand for something other than themselves"14. Thus, "when we speak of symbols we refer to comprehensible (i.e. 'graspable') entities, whether objects, ideas, or patterns of behaviour, which represent, by means of an underlying rationale, some more or less abstract notion (power, social or group unity, 'maleness' and 'femaleness', life, the dangerous and unfamiliar, are examples), to which social or cultural value, either positive or negative, is attached"15.

Within the category of ritual, objects, ideas as well as acts, have a symbolic nature. Supernatural, or non-empirical, powers like spirits and gods are thus also symbols ${ }^{16}$. Unless I have totally misunderstood him, Beattie's thought on magic and religion requires a distinction to be made between the literal level on which people believe themselves to be interacting with supernatural beings whose reality they do not doubt, and a deeper, symbolic level on which people's religious activities as well as the supernatural

\footnotetext{
9 Beattie 1964, 72.

${ }^{10} \mathrm{Cf}$. ib. 202.

11 Cf. ib. 72.

12 Cf. Beattie 1970, 241.
}

13 Cf. Leach 1966, 404; 1968, 523.

14 Beattie 1964, 69.

15 Beattie 1970, 242.

16 Cf. Beattie 1964, 224. 
beings are correctly understood as "symbolizing certain important aspects of the physical and socio-cultural environment" 17 . When applied to magical acts in particular this means that belief in the efficaciousness of magic belongs to the literal level. On the symbolic level the actor is not doing anything at all, he is saying something.

3. When turning now to Beattie's account of magic, one feels the need for a detailed analysis of at least one particular magical rite where his theoretical framework could be demonstrated and applied, if not verified. Such an analysis might have enabled him to show, first, that the magical act is basically a means for saying something, not doing something; second, as the rite is symbolic, how it relates to its significatum by means of an underlying rationale; third, that the significatum is an abstract idea which has a social value; and fourth, why an essentially expressive and symbolic act should be believed to be effective by the actors. Unfortunately, however, I have been unable to find an analysis of this kind in Beattie's writings. His account of magic moves on a much more general and abstract level. Thus he uses the generalized and almost unavoidable magical rite where a man sticks a pin in a wax model of his enemy while uttering the appropriate spell ${ }^{18}$. I hasten to add, however, that the kind of ritual micro-analysis that I am missing is of a kind that probably would be out of place in the writings of Beattie referred to in this paper. His main concern is undoubtedly to argue for the very general thesis that magical acts belong to the category of expressive action. The man who attempts to kill his enemy by means of magic is engaged in an enterprise different in kind from that of the person who waylays and murders him. The first man says what he wants, the other does what he wants ${ }^{19}$. This position is quite the opposite of that of Frazer who thought of magical rites as acts performed in order to achieve particular ends, the acts being causes that in a mechanical way lead to the desired goal. Beattie considers Frazer's theory to represent "a travesty of magical thinking, which is essentially symbolic thinking" Magical acts cannot be understood on the basis of what the actors want to accomplish by performing them: "Serious mistakes have arisen from attempts to interpret types of behaviour which are primarily symbolic in intention as though they were misguided attempts to be practical and scientific." 21

Magical acts should therefore not be understood as inadquate means for attaining empirical aims, but as dramatic assertions which may be ends in themselves. When writers like Malinowski and Evans-Pritchard list a number of reasons why people do not disclose the futility of their magic, they do not mention this reason which is the most important of them all ${ }^{22}$.

\footnotetext{
17 Beattie 1970, 263.

18 Cf. Beattie 1966, 63.

19 Cf. ib.
}

${ }^{20}$ Beattie 1964, 66

21 Ib. 72.

${ }^{22}$ Cf. Beattie 1966, 68 . 
The examples of magical acts given by Beattie in order to illustrate his general thesis, belong to the Frazerian category of imitative magic. In such cases of magic, based on "the law of similarity", it is not difficult to demonstrate that the magical act is related to its significatum by means of an underlying rationale. The act of sticking a pin in a wax model of your enemy comes into this category, and so does the pouring of water or the producing of heavy smoke in order to make rain. As I shall argue later, we clearly have to do with symbolism in cases like these, but Beattie generalizes from these cases and argues that all kinds of magic are symbolic.

According to Beattie's definition of symbol, magical acts as symbols should refer to more or less abstract notions with social value and preferably to the social or natural order. Thus when people perform a rainmaking ceremony by means of the pouring of water or the producing of heavy smoke, they symbolically assert the importance that they attach to rain and their earnest desire that it should fall ${ }^{23}$. And when a man sticks a pin in a wax model of his enemy he is expressing his desire for the enemy's death by making a little picture of what he wants ${ }^{24}$. Although it is hardly an abstract notion, rain clearly qualifies as a social value. Also the death of an enemy may imply a social value, but not necessarily so, and again no abstract notion would seem to be involved.

While it is obvious that rituals are symbolic for Beattie, he is well aware that they need not be symbolic for the actor: "The total procedures which we label 'magical' need not be, and often are not, viewed by their practitioners as purely symbolic (or even as symbolic at all). They are ways of getting what they want, what is done in such and such a situation in a given culture." 25

Now it is quite obvious that a person who performs a magical rite has no difficulties in verbalizing and making explicit that he is acting in order to achieve a particular end, magical acts are clearly instrumental on the literal level. Beattie therefore raises the crucial question "in what sense, if any, can we say that people's institutionalized behaviour is symbolic if, as may well be the case, they themselves do not seem to know what it is?" ${ }^{26}$

The most important argument for his thesis seems to be that the symbolic level of consciousness is implicit or unconscious, but that the anthropologist can show that it really does exist by placing the rites and symbols which he observes in a total social and cultural setting ${ }^{27}$. The conclusion must be that people who perform magical rites act explicitly and consciously on the instrumental and literate level, but not on the expressive level which is the level on which an adequate understanding of such acts must be obtained.

\footnotetext{
${ }^{23}$ Cf. Beattie 1964, 203.

24 Cf. Beattie 1966, 66.

${ }^{25}$ Beattie 1970, 251.
}

26 Beattie 1966, 66.

27 Cf. ib. 67. 
To the last question, why should people who perform magical acts which are really expressive and symbolic be convinced of their efficaciousness, Beattie's answer is that the conviction of efficaciousness is grounded in their symbolic quality. "What I am asserting, then, is that fundamentally ritual's efficacy is thought to lie in its very expressiveness." 28

In my opinion this assertion can best be illustrated by means of magical acts in which the relation between the signans and the significatum has a metaphorical nature, that is, rites which are based on the Frazerian "law of similarity". Although I shall later modify somewhat Beattie's argument, in these particular cases we can understand that the dramatized expression of a wished-for state of affairs may convince the actors that this dramatization is an adequate means for attaining it. But Beattie argues that all rites which are regarded by the actors as efficacious, should be understood on the background of the expressive nature of these acts.

Beattie's arguments for this assertion are very brief. He quotes with approval Malinowski's assertion to the effect that the expression of emotions in verbal utterances and gestures have a certain power. And the explanation for this is to be found in the psychology of children. To the child words are not merely means of expression but efficient modes of action ${ }^{29}$. $\mathrm{He}$ thus seems to endorse, at least in part, Malinowski's emotionalist theory of magic.

As Beattie explicitly states, the general thesis that magical acts are believed to be efficacious because they are expressive and symbolic, cannot be validated by reference to what informants say. If the Azande state that their magic is effective because of the power present in the magical substances used in the rites, "by what conceivable right do we assert that these informants are mistaken, that we know better than they do what they 'really' think, and that even though they do not know it, what underlies their behaviour is a belief in the power of symbolic expression itself?" 30

In attempting to anser this question he refers to his previous arguments for the ascription of symbolism in cases where it is unknown to the actors, and then advances the assertion that no other explanation of the thought that underlies ritual institutions can make sense of people's behaviour ${ }^{31}$.

4. During the last twenty years or so, symbolist theories of magic and religion have been discussed and criticised by anthropologists (Horton, Goody, Spiro), sociologists (Peel, Turner, Runciman), philosophers (Jarvie, Agassi, Skorupski)., and students of comparative religion (Ray). I cannot refer or take a stand on these discussions here. My own approach is most probably to be labeled "literalist", a term which in the discussions
${ }^{28}$ Ib. 69.
${ }^{30} \mathrm{Ib}$.
29 Cf. ib.
${ }^{31}$ Cf. ib. 
has been used to characterize those students of traditional religions who are opposed to the symbolist thesis as well as in some degree to the more extreme intellectualist approach of the neo-Tylorians whose most energetic spokesman is Horton. In my perspective it becomes necessary to question the fruitfulness of Beattie's classification of human behaviour in expressive and instrumental, and consequently his thesis that magic and religion are essentially symbolic. Instead of a distinction formulated from the observer's point of view, I prefer a distinction made from the point of view of the actor in accordance with the Weberian principle of Verstehen.

Beattie defines instrumental activity as activity which must be understood "in terms of the consequences it aims at and achieves"32. Instrumental activities are thus not only goaldirected, but they are also means that really (that is, as judged by our own reality definitions) lead to the desired goal. On the basis of an observer oriented definition of instrumentality it is obvious that magical acts cannot be instrumental because we know that magic does not work. But when Beattie states that magical acts, which "in reality" are expressive, also have an instrumental aspect, he defines instrumentality from the actor's point of view. The concept instrumental is thus ambiguous, and our dilemma consists in whose definition we should choose, that of the observer or that of the actor. As we have seen, Beattie attempts to solve this dilemma by postulating that the actors on some level of consciousness somehow are aware that magical acts are really symbolic and expressive. He thus approaches the position of Marett who saw magic "as a more or less clearly-recognized pretending, which at the same time is believed to project itself into an ulterior effect" 33 . But Beattie is conscious of the fact that one is confronted by very serious problems in verifying the thesis that magical acts are symbolic when the actors do not intend them as such. Beattie finds no reason to doubt that the actors are of the serious opinion that their magical acts are adequate means for obtaining certain ends. Marett's magician somehow knows that he is pretending, that his act is symbolic in the sense of not real, in other words, he suppresses his unbelief in the magical act. But Beattie knows that the actors are convinced that their magical acts are effective, that they are not pretending. At the same time Beattie knows that magical acts cannot have the effects imputed to them by the actors. I find it hard to see that Beattie has succeeded in verifying the thesis that magical acts for the actor on any level of consciousness, are not instrumental, but expressive and symbolic. The concepts of expressive and instrumental I find very useful, but in my opinion they should be used within the frame of reference of the actor. From this perspective magical acts are necessarily instrumental.

5. In the foregoing I have been critical of the central symbolist thesis which maintains that religion and magic as such have a symbolic nature

${ }^{32}$ Beattie 1964, 72.

33 Marett 48. 
whose referents are the social, or alternatively, the natural order. I will not deny that we often find symbols in magic and religion, of course we do. Our first task must therefore be the construction of a fruitful concept of symbol and the emphasis that I place on the actor's point of view demands that we for our understanding of the nature of symbols must start with what are intended as symbols by the actors. This does not mean that it is always obvious when an object is symbolic, or a statement a metaphor, there will always be a number of border line cases. What I should like to do here is to suggest a concept of symbol which harmonizes with a "literalist" conception of magic and religion, and more particularly, one that is fruitful for the understanding of magical acts. By the term "ritual symbol", then, I shall understand a physical object (or the objectivation of linguistic elements) which stands in a culturally defined relationship of representation or participation to an entity in a given socially constructed world. I find no particular reason to emphasize that the signification should have a logical rationale, or have a metaphoric character ${ }^{34}$. Nor do I want to stipulate that the significatum should be an abstract notion with social value. What I should like to emphasize is that the symbol object, the signans, is quite concretely a stand-in for its significatum. In ritual situations it consequently tends to be treated $a s$ if it is the entity which it represents. I fulle agree with Beattie and others ${ }^{35}$ when they underline the tendency of the entity symbolized to participate in or float over into the symbol object.

If we apply this perhaps somewhat restrictive definition of symbol, the property "symbolic" can also be ascribed to magical acts provided that the rite includes a symbol on which the magical act is an operation. In such cases the action with reference to the symbol will as a whole represent an action with reference to the entity symbolized. The symbolic-ritual act must be defined on the basis of the use of a symbolic object in the ritual ${ }^{36}$. Proceeding from this understanding of ritual symbols I shall-following Skorupski-suggest that a particular type of magical acts are based on a cognitive pattern that implies control by means of symbols. The characteristic features of this form of magic is probably best seen when it is compared with some other elementary forms of magic. I want to emphasize, however, that these different forms of magic are not to be understood as an exhaustive classification within a field with well defined limits. In any given magical act, moreover, two or more of these elementary forms can be combined.

6. The elementary form of magic that is of central concern in the present context can briefly be called symbolic magic. The magical act is typically

${ }^{34}$ Cf. Leach 1976, 12 ff.

${ }^{36}$ Cf. Skorupski 119, 123.

35 Cf. Firth 1973, 15 f. 
an operation on objects that serve as symbols, or alternatively, on objectivated linguistic elements, most often the names of persons and things. In those cases where the rite includes a spell, this serves typically to identify the ritual symbol with the entity which it represents. The cognitive pattem on which this kind of magic is based, Skorupski calls symbolic or mimetic identification: "Some form of change is produced in an object, $s$, which is taken as standing for, or 're-presenting', the goal object, $g$. So, $s$ 'is' $g$. Therefore the same change is produced in $g .{ }^{\text {" }} 37$

As an example of this form of magic we can use the by now very familiar operation on the wax figure. When a magician sticks a pin in a wax model that represents his enemy, this enemy undergoes the same change as the wax model which is a stand-in for him in the rite. His breast is pierced and he dies. In cases belonging to this kind of magic I shall presuppose that the actor knows that the ritual object is a symbol. If he is asked I expect that he can give an explicit answer to the effect that the ritual object is a stand-in for the entity he wants to affect. For the actor the act is instrumental because he is convinced that he can exercise real control by means of the manipulation of symbols. The symbol is here to be seen as being connected with the instrumental aspect of the magical act as seen from the point of view of the actor. This position is rather different from that of Beattie who connects the symbol with the expressive aspect of the magical act and the belief in its efficacy with the literal level, as seen from the point of view of the observer. The conviction of control by means of symbols should not be interpreted by us as "make-believe" or symbolic in the sense of not real as Marett maintained ${ }^{38}$. Neither is it the case that the actor fails to disclose the falsity of his own magic because overpowering emotions shut off his cognitive reality definitions ${ }^{39}$.

The kind of magic I am here concerned with comprises the Frazerian imitative magic, but I think that it is not necessary to emphasize-as Frazer does-that there should be an element of similarity between symbol and entity symbolized. Thus in rites of vengeance magic that I observed among the Zinza of Tanzania, pepperfruits were used to represent the persons who were the targets of the magical act. Also Frazer's category of contagious magic belongs to the present kind of magic. Nail parings, excrements, hair, shreds of clothing, etc., are in magical acts used as symbols of the person (or other entity) to whom they used to belong.

In this connection there is another point of considerable theoretical importance that must be mentioned. As we know Frazer viewed the magical act and its effect as two quite distinct events between which there was a causal relationship. But in the case of symbolic magic we are well advised

${ }^{37}$ Ib. 135.

${ }^{39}$ Cf. Widengren $6 \mathrm{f}$.

${ }^{38} \mathrm{Cf}$. Marett $41 \mathrm{ff}$. 
to consider whether the operation on the symbol is seen as merging with the effect on the entity symbolized so that there is only one event ${ }^{40}$.

In the other elementary forms of magical acts the ritual use of symbols is not a necessary feature. In the cognitive pattern which can be called the magical power of words, it is ritual language itself—called "the formula spell" by Evans-Pritchard ${ }^{41}$-in which the efficient power is believed to inhere. Quite a few of the examples given by Malinowski for the Trobrianders $^{42}$, and by Firth for the Tikopia ${ }^{43}$ are good examples of magical acts based on this cognitive pattern.

Skorupski suggests that the two forms of magic mentioned above may be considered by us as being magic in the strict sense of the term. His argument is that in both these cases we have to do with cognitive patterns that are based on a lack of differentiation between natural and culturally defined connections ${ }^{44}$. However this may be, I shall briefly mention two other kinds of rites often characterized by anthropologists and others as magical. The first one comprises acts based on the cognitive pattern that Skorupski calls contagious transfer ${ }^{45}$. In this kind of magic a property which according to the actors is present in a certain substance is by means of some physical contact transferred to a person or some other entity. (It should be emphasized that this kind of magic is not identical with Frazer's contagious magic.) The second kind can be called interactive magic. Rites belonging to this category are based on the belief that the efficaciousness of the act is due to some mediating supernatural agency like the power in magical substances or some personal supernatural being. The spells used in these rites typically take the form of orders given to the agency which brings about the desired effect.

\section{Bibliography}

Beattie, J., 1964, Other cultures. London.

- 1966, Ritual and social change. Man 1.

- 1970, On understanding ritual. Rationality. Ed. B. Wilson. London.

Evans-Pritchard, E., 1929, The morphology and function of magic. American anthropologist 31 .

Firth, R., 1967, Tikopia ritual and belief. London.

- 1973, Symbols public and private. London.

Horton, R., 1973, Levy-Bruhl, Durkheim and the scientific revolution. Modes.

Modes, 1973, Modes of thought. Ed. R. Horton, Ruth Finnegan. London.

Leach, E., 1954, Political systems of highland Burma. London.

- 1966, Ritualization in man in relation to conceptual and social development. Royal Society of London, Philosophical transactions. Series B 251.

- 1968, Ritual. International encyclopaedia of the social sciences 13.

- 1969, Genesis as myth and other essays. London.

40 Cf. Skorupski $141 \mathrm{ff}$.

41 Cf. Evans-Pritchard 625.

42 Cf. Malinowski $136 \mathrm{ff}$.
${ }^{43}$ Cf. Firth 1967, $195 \mathrm{ff}$.

${ }_{44}$ Cf. Skorupski $156 \mathrm{f}$.

${ }^{45}$ Cf. ib. $134 \mathrm{f}$. 
- 1976, Culture and communication. Cambridge.

Malinowski, B., 1966, Coral gardens and their magic 1. London.

Marett, R., 1914, The threshold of religion. London.

Peel, J., 1969, Understanding alien belief-systems. British Journal of sociology 20.

Runciman, W., 1969, The sociological explanation of "religious" beliefs. Archives européennes de sociologie 10.

Skorupski, J., 1976, Symbol and theory. Cambridge.

Widengren, G., 1969, Religionsphänomenologie, Berlin. 